\title{
Hepatoprotective Mechanisms of Taxifolin on Carbon Tetrachloride-Induced Acute Liver Injury in Mice
}

\author{
Chao-Lin Yang ${ }^{1} \mathbb{D}$, Yu-Shih Lin ${ }^{2}$, Keng-Fan Liu ${ }^{3}$, Wen-Huang Peng ${ }^{3, *}$ and Chih-Ming Hsu ${ }^{4, *}$ \\ 1 Ph.D. Program for Biotechnology Industry, College of Biopharmaceutical and Food Sciences, China Medical \\ University, Taichung 40402, Taiwan; u105307001@cmu.edu.tw \\ 2 Department of Pharmacy, Chiayi Chang Gung Memorial Hospital, Chiayi 61363, Taiwan; \\ yohimba@cgmh.org.tw \\ 3 Department of Chinese Pharmaceutical Sciences and Chinese Medicine Resources, College of Chinese \\ Medicine, China Medical University, Taichung 40402, Taiwan; cell77821@gmail.com \\ 4 Department of Medical Education, Chiayi Chang Gung Memorial Hospital, Chiayi 61363, Taiwan \\ * Correspondence: whpeng@mail.cmu.edu.tw (W.-H.P.); kan200068@cgmh.org.tw (C.-M.H.); \\ Tel.: +886-4-22053366 (W.-H.P.); +886-5-3621000-3128 (C.-M.H.)
}

Received: 26 September 2019; Accepted: 28 October 2019; Published: 4 November 2019

check for updates

\begin{abstract}
Objective: To investigate the hepatoprotective mechanisms of taxifolin in mice with acute liver injury induced by $\mathrm{CCl}_{4}$. Methods: ICR (Institute of Cancer research) mice were orally pretreated using taxifolin for 7 consecutive days and were then given single intraperitoneal (i.p.) injections of $0.2 \% \mathrm{CCl}_{4}(10 \mathrm{~mL} / \mathrm{kg}$ body weight, i.p.). Liver injury was then determined using assays of serum alanine aminotransferase (sALT) and serum aspartate aminotransferase (sAST). Further, to investigate the hepatoprotective mechanisms of taxifolin, we determined malondialdehyde (MDA) levels and superoxide dismutase (SOD), glutathione peroxidase (GPx), and glutathione reductase (GRd) activities. Results: $\mathrm{CCl}_{4}$-induced liver injury led to significant increases in sALT and sAST activities, and these increases were limited by taxifolin and silymarin (Sily) pretreatments. Histological analyses also indicated that taxifolin and Sily decreased the range of liver lesions in $\mathrm{CCl}_{4}$-treated mice and vacuole formation, neutrophil infiltration, and necrosis were visibly reduced. In addition, SOD, GPx, and GRd activities were increased and MDA levels were decreased after taxifolin and Sily treatments. Conclusion: The hepatoprotective mechanisms of taxifolin and Sily are related to decreases in MDA levels presumably due to increased antioxidant enzyme activities. These outcomes suggest that taxifolin mitigates acute liver injury resulted from $\mathrm{CCl}_{4}$ in mice, demonstrating the hepatoprotective effects of taxifolin.
\end{abstract}

Keywords: liver injury; taxifolin; antioxidant enzymes; carbon tetrachloride; mice

\section{Introduction}

The formation and degradation of reactive oxygen species (ROS) in all aerobic organisms is commonly known; further, ROS mediate various intracellular signaling cascades [1]. The excessive production of ROS induces oxidative stress in human bodies, causing damage to proteins, DNA, and lipids and leading to degenerative and pathological disease states [2]. Some environmental factors, such as cigarette smoke and certain drugs, can increase free radical activities in the liver. To a certain extent, endogenous antioxidants can maintain oxidative equilibrium and prevent cell damage from excess ROS under such conditions [3].

The liver plays an essential role in various metabolic processes; moreover, liver injury leads to various severe morbidities. Various toxic chemicals and drugs and infection with viruses, such as hepatitis, cause liver injury [4]. Carbon tetrachloride $\left(\mathrm{CCl}_{4}\right)$ metabolism via cytochrome $\mathrm{P} 450$ leads to 
the formation of trichloromethyl radicals $[4,5]$ that rapidly react with lipids and proteins, in particular, causing lipid peroxidation of cell membranes [6]. Previous research indicates that antioxidants inhibit the formation of free radicals and protect liver tissues against $\mathrm{CCl}_{4}$-induced injury via blocking deleterious lipid peroxidation reactions. To exploit these mechanisms, the antioxidant activities of various herbs and health foods have been comprehensively investigated in recent years, and numerous active chemical compounds have been identified [7].

Taxifolin is present at low levels in plants but has been identified as a bioflavonoid pseudovitamin P. Taxifolin is isolated from larch plants, such as larch and Douglas fir, in which it is present at $2-3 \%$.

Taxifolin reportedly prolongs life by $40 \%$ and $37 \%$ in mice with leukemia [8]. Strong antibacterial activity has also been demonstrated against Staphylococcus aureus, Escherichia coli, Shigella, and Salmonella typhi. Moreover, the biological activities of taxifolin have been related to reduced free radical activities in humans and are associated with anti-aging and antitumor effects and inhibition of cytopathic effects [9]. Although the larch plant has been traditionally used to cure liver disease, the related mechanisms have not yet been scientifically validated. Therefore, we investigated the hepatoprotective antioxidant activities of taxifolin in $\mathrm{CCl}_{4}$-induced acute liver injury in mice. To this end, we monitored liver injury according to the levels of serum alanine aminotransferase (sALT) and serum aspartate aminotransferase (sAST) [10]. Histopathological changes were also observed in liver biopsies, and malondialdehyde (MDA) levels were determined along with antioxidant enzymes superoxide dismutase (SOD), glutathione peroxidase (GPx), and glutathione reductase (GRd) activities [11].

\section{Materials and Methods}

\subsection{Animals}

Male ICR mice (20-25 g) purchased from BioLasco Charles River Technology (Taipei, Taiwan) were used in the study. The animals were raised in a temperature-controlled room of the Animal Center of China Medical University at $22 \pm 1{ }^{\circ} \mathrm{C}$ (relative humidity: 55\% $\pm 5 \%$; light and dark cycle: $12 \mathrm{~h}$ light $/ 12 \mathrm{~h}$ dark) for at least one week. Mice were provided food and clean water ad libitum. All animal tests were performed as per the NIH Guidelines for the Care and Use of Laboratory Animals. Further, the Committee for Animal Research at China Medical University approved the experimental protocol (IACUC 2018-249).

\section{2. $\mathrm{CCl}_{4}$-Induced Hepatotoxicity}

Mice were randomly separated into 6 groups $(n=10)$. Mice in the control and $\mathrm{CCl}_{4}$ groups were orally administered distilled water, and those in the Sily group were orally administered Sily at $200 \mathrm{mg} / \mathrm{kg}$ in 1\% carboxymethylcellulose [12]. Mice in the taxifolin group were orally administered taxifolin at 100, 150, and $200 \mathrm{mg} / \mathrm{kg}$ for 7 consecutive days. Further, 1 hour after the final pretreatment, $\mathrm{CCl}_{4}$ was intraperitoneally (i.p.) injected into all mice except those in the control group, which received equivalent volumes of olive oil (i.p.). Mice were euthanized under anesthesia at $24 \mathrm{~h}$ after $\mathrm{CCl}_{4}$ injections, and blood was collected, followed by centrifugation at $3000 \mathrm{rpm}$ (Beckman GS-6R, Germany) at $4{ }^{\circ} \mathrm{C}$ for $30 \mathrm{~min}$ to separate the serum. Subsequently, sALT and sAST activities were measured by spectrophotometric diagnostic kits (Roche, Germany). Removal of liver tissues was performed for histological analyses, MDA assays, and measurements of antioxidant enzymatic activities.

\subsection{Histological Analyses}

Fresh liver tissues from the same lobes were collected, trimmed to a thickness of about $2 \mathrm{~mm}$, and then fixed in 10\% buffered formaldehyde solution. Fixed tissues were cut into sections of $2 \mu \mathrm{m}$ and stained using hematoxylin and eosin (H\&E) followed by examination under a light microscope (Olympus, Yuan Li Instrument Co., Ltd., Taichung Branch.). 


\subsection{MDA Assays}

The levels of MDA were determined by thiobarbituric acid reacting substance method. Absorbance was determined at $532 \mathrm{~nm}$, and the levels of MDA were expressed as $\mu \mathrm{mol} / \mathrm{mg}$ protein [12].

\subsection{Measurements of Antioxidant Enzyme Activity}

SOD activities were determined as the procedure described by Misra and Fridovich [13]. Absorbance was measured at $480 \mathrm{~nm}$ for $4 \mathrm{~min}$; one unit of SOD activity was expressed as the enzyme amount required for inhibiting epinephrine oxidation by $50 \%$.

GPx activities were determined as the protocol by Flohe and Gunzler [14]. Absorbance was measured at $340 \mathrm{~nm}$ for $180 \mathrm{~s}$, and a molar extinction coefficient of $6.22 \times 10^{-3}$ was used to calculate enzyme activity. In these experiments, one unit of activity is defined as that needed to oxidize NADPH at a rate of $1 \mathrm{mM} / \mathrm{min} / \mathrm{mg}$ protein.

As per the method by Carlberg and Mannervik [15], in which absorbance is measured at $340 \mathrm{~nm}$ for $3 \mathrm{~min}$ and a molar extinction coefficient of $6.22 \times 10^{-3}$ was used to calculate product concentrations, GRd activity was determined. In these assays, one unit of activity is defined as that needed to oxidize $\mathrm{NADPH}$ at a rate of $1 \mathrm{mM} / \mathrm{min} / \mathrm{mg}$ protein.

\subsection{Statistical Analysis}

Means \pm standard errors of the mean (SEM) are used to present the data. SPSS software was used to perform statistical analyses. One-way ANOVA followed by Tukey-Kramer tests (Kramer's Method) was used to identify significant differences. Quantitative analyses of histological data were performed using nonparametric Kruskal-Wallis tests followed by Mann-Whitney U-test. $p<0.05$ was considered statistically significant.

\section{Results}

\section{1. $\mathrm{CCl}_{4}$-Induced Acute Liver Injury}

The hepatoprotective effects of taxifolin in mice with $\mathrm{CCl}_{4}$-induced liver injury are presented in Figure $1 \mathrm{~A}, \mathrm{~B} . \mathrm{CCl}_{4}$ treatments significantly increased the activities of sALT and sAST. However, pretreatments with taxifolin $(200 \mathrm{mg} / \mathrm{kg})$ and Sily $(200 \mathrm{mg} / \mathrm{kg})$ significantly reduced the elevated activities of sALT and sAST induced by $\mathrm{CCl}_{4}$ in mice.

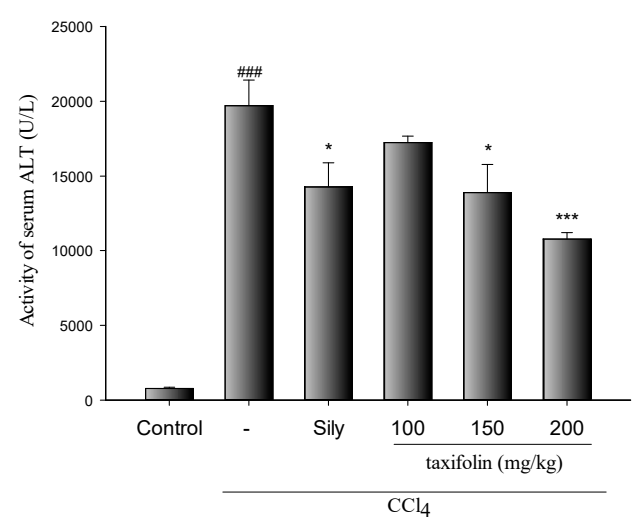

(A)

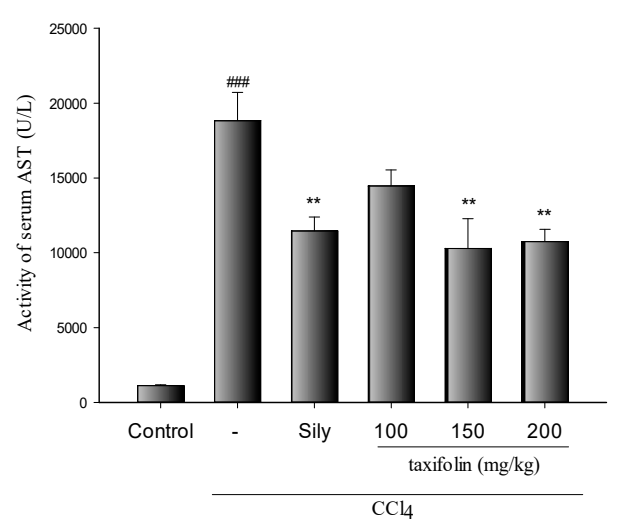

(B)

Figure 1. Effects of taxifolin and Sily on the activities of serum alanine aminotransferase (sALT) (A), and serum aspartate aminotransferase (sAST) (B) in carbon tetrachloride $\left(\mathrm{CCl}_{4}\right)$-treated mice; data are presented as means $\pm \operatorname{SEM}(n=10)$. \#\#\# $p<0.001$, compared with the control group; ${ }^{*} p<0.05$, compared with the $\mathrm{CCl}_{4}$ group. One-way ANOVA followed by Tukey-Kramer tests was used to identify the differences. 


\subsection{Histological Analyses}

As shown in Figure 2 and Table 1, $\mathrm{CCl}_{4}$ treatments led to the formation of vacuoles and necrosis in histological sections, and these indicators of tissue injury were reduced in animals that were pretreated with taxifolin (150 and $200 \mathrm{mg} / \mathrm{kg}$ ) and Sily $(200 \mathrm{mg} / \mathrm{kg})$.
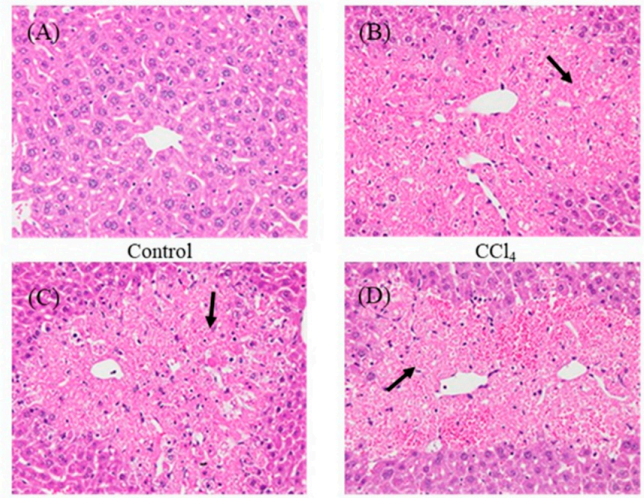

$\mathrm{CCl}_{4}+$ Sily $(200 \mathrm{mg} / \mathrm{kg})$
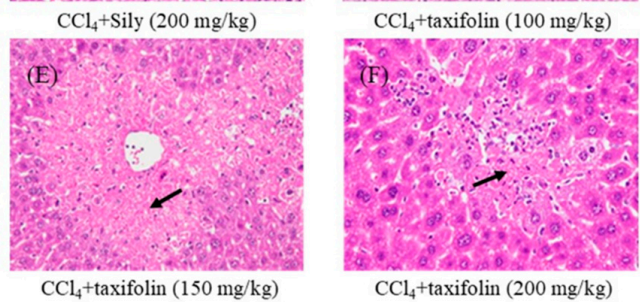

Figure 2. Histopathological changes in mice with acute hepatic injury induced by $\mathrm{CCl}_{4}$; images are presented from control and $\mathrm{CCl}_{4}$ treated mice with and without Sily and taxifolin pretreatments. Normal glycogen infiltration in a mouse of the control group (A); in liver sections from mice treated with $\mathrm{CCl}_{4}$, hematoxylin and eosin (H\&E) staining showed hepatocellular vacuolization and moderate hepatic necrosis in portal areas (B). Sily (C) $100 \mathrm{mg} / \mathrm{kg}$ taxifolin (D), $150 \mathrm{mg} / \mathrm{kg}$ taxifolin (E), and $200 \mathrm{mg} / \mathrm{kg}$ taxifolin (F) pretreated $\mathrm{CCl}_{4}$-induced hepatic injury mice; $400 \times$.

Table 1. Quantitative summary of the protective effects of Sily and taxifolin on hepatic damage induced by $\mathrm{CCl}_{4}$ based on histopathological observations.

\begin{tabular}{|c|c|c|c|c|c|c|c|}
\hline \multirow{3}{*}{ Organ } & \multirow{3}{*}{ Lesions } & \multicolumn{6}{|c|}{ Group } \\
\hline & & \multirow{2}{*}{$\mathbf{N}$} & \multirow{2}{*}{$\mathrm{CCl}_{4}$} & \multirow{2}{*}{ Sily } & \multicolumn{3}{|c|}{ Taxifolin (mg/kg) } \\
\hline & & & & & 100 & 150 & 200 \\
\hline & Vacuolization $^{1}$ & $0 * * *$ & $1.4 \pm 0.18$ & $0.8 \pm 0.13^{* *}$ & $0.8 \pm 0.14$ & $1 \pm 0.15^{*}$ & $0.5 \pm 0.17^{* * *}$ \\
\hline & Coagulative necrosis & $0^{* * *}$ & 4 & $3.0 \pm 0.31$ * & $3.9 \pm 0.10$ & $3.5 \pm 0.17$ & $2.6 \pm 0.43^{*}$ \\
\hline
\end{tabular}

Lesions were graded from 1 to 5 as per the severity: $1=\operatorname{minimal}(<1 \%) ; 2=\operatorname{slight}(1-25 \%) ; 3=$ moderate $(26-50 \%)$; $4=$ moderate/severe (51-75\%); and $5=$ severe/high $(76-100 \%) ; .^{*} p<0.05,{ }^{* *} p<0.01$, and ${ }^{* * *} p<0.001$, compared with the $\mathrm{CCl}_{4}$ group.

\subsection{MDA Levels}

In lipid peroxidation assays, MDA levels (Figure 3) were significantly increased in mice with liver injury induced by $\mathrm{CCl}_{4}$. Yet, in mice of the taxifolin and Sily groups, hepatic MDA levels mediated by $\mathrm{CCl}_{4}$ were significantly lowered. 


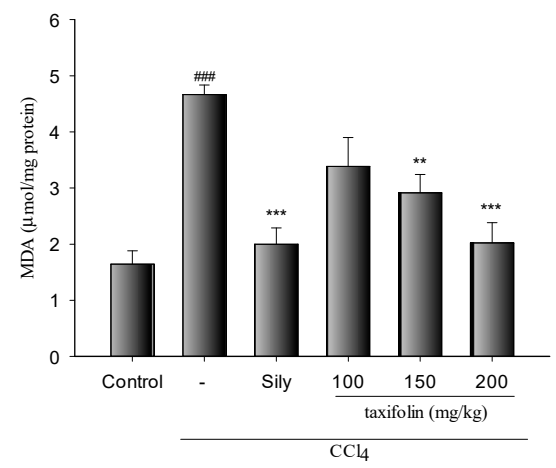

Figure 3. Taxifolin and Sily effects on hepatic MDA levels in mice with hepatic injury induced by $\mathrm{CCl}_{4}$; data are presented as means \pm SEM $(n=10)$. \#\#\# $p<0.001$, compared with the control group; ${ }^{* * *} p<0.001$, compared with the $\mathrm{CCl}_{4}$ only group; ${ }^{* *} p<0.05$, compared with the $\mathrm{CCl}_{4}$-only group; One-way ANOVA followed by Tukey-Kramer tests was used to identify the differences.

\subsection{Antioxidant Enzyme Activities}

SOD, GPx, and GRd activities were significantly decreased in mice with $\mathrm{CCl}_{4}$-induced liver damage than in the control group (Figure 4). The decreases in these activities were significantly ameliorated via pretreatments with taxifolin $(200 \mathrm{mg} / \mathrm{kg})$ and Sily $(200 \mathrm{mg} / \mathrm{kg})$.

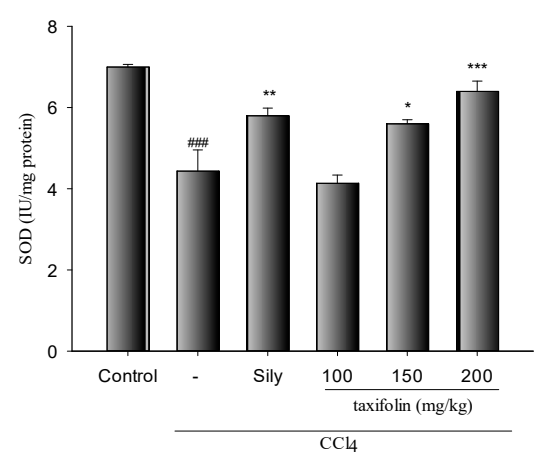

(A)

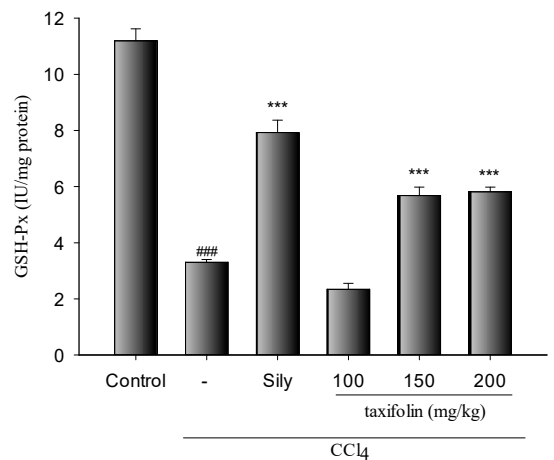

(B)

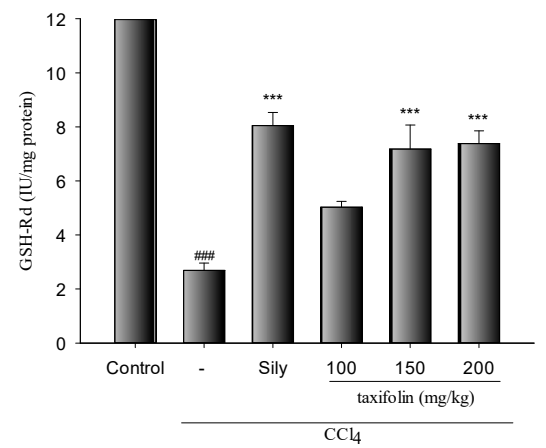

(C)

Figure 4. Taxifolin and Sily effects on the activities of hepatic superoxide dismutase (SOD) (A), glutathione peroxidase (GPx) (B), and glutathione reductase (GRd) (C) in $\mathrm{CCl}_{4}$-treated mice; data are presented as means \pm SEM $(n=10)$. \#\#\# $p<0.001$, compared with the control group; ${ }^{*} p<0.05$ and ** $p<0.01$, compared with the $\mathrm{CCl}_{4}$ group. One-way ANOVA followed by Tukey-Kramer tests was used to identify the differences. 


\section{Discussion}

Enhanced sAST and sALT activities are generally associated with hepatic structural damage [16]. Accordingly, compared with the control group, the present $\mathrm{CCl}_{4}$-treated mice had elevated sALT and sAST activities, and vacuole formation and extended necrotic areas around central veins indicated increased hepatic cell injury. Under these conditions, taxifolin pretreatments were significantly protective against histological and biochemical indicators of liver injury and $\mathrm{CCl}_{4}$-induced hepatotoxicity.

A major index of $\mathrm{CCl}_{4}$-induced liver injury is lipid peroxidation [6], and the endproduct MDA is widely used as a free radical-mediated lipid peroxidation marker [17]. Among contributors to the free radical milieu, NO is produced by l-arginine conversion to l-citrulline by inducible nitric oxide synthase (iNOS). Overproduced NO has been widely associated with inflammation and hepatic injury, and is abundantly implicated because it reacts with superoxide anions to form peroxynitrite, which acts directly as a lipid oxidant that elevates hepatic MDA levels in injured livers. In this study, hepatic MDA levels increased by $\mathrm{CCl}_{4}$ treatments were significantly decreased by pretreatment with taxifolin $(0.5$ and $1.0 \mathrm{~g} / \mathrm{kg})$. This result suggested taxifolin possessed potent hepatoprotective effects.

In a previous study, ROS after $\mathrm{CCl}_{4}$ treatments inactivated the antioxidant enzymes SOD, GPx, and GRd [17]. Superoxide anions are converted by SOD to the toxic intermediate $\mathrm{H}_{2} \mathrm{O}_{2}$ [18], further metabolized to nontoxic products by GPx. In this process, GSH is oxidized to GSSG and then recycled through GRd-mediated reduction to GSH [19]. Herein, we report significant decreases in SOD, GPx, and GRd activities following acute $\mathrm{CCl}_{4}$ damage. We also show that pretreatments with taxifolin significantly ameliorate these deleterious changes. Collectively, the present data suggest that taxifolin inhibits ROS production by promoting hepatic antioxidant activities, leading to greater protection against liver injury induced by $\mathrm{CCl}_{4}$.

\section{Conclusions}

In all the liver injury tests in this study, taxifolin exhibited hepatoprotective activities against acute liver toxicity induced by $\mathrm{CCl}_{4}$ in mice. Taxifolin's hepatoprotective mechanisms should be associated with the inhibition of lipid peroxidation via the increase in the activities of antioxidant enzymes, such as GPx, SOD, and GRd, rather than a direct ROS scavenging effect of taxifolin. The present experiments provide evidence that taxifolin has hepatoprotective effects.

Author Contributions: Investigation, C.-L.Y.; project administration, C.-L.Y.; writing-original draft, C.-L.Y.; writing-review \& editing, C.-L.Y.; funding acquisition, C.-M.H. and Y.-S.L.; supervision, C.-M.H., W.-H.P., Y.-S.L. and K.-F.L.

Funding: This research and the APC was funded by Chiayi Chang Gung Memorial Hospital, grant number CMRPG6G0161.

Conflicts of Interest: The authors declare no conflict of interest.

\section{References}

1. Nordberg, J.; Arner, E.S. Reactive oxygen species, antioxidants, and the mammalian thioredoxin system. Free Radic. Biol. Med. 2001, 31, 1287-1312. [CrossRef]

2. Kietzmann, T.; Gorlach, A. Reactive oxygen species in the control of hypoxia-inducible factor-mediated gene expression. Semin. Cell Dev. Biol. 2005, 16, 474-486. [CrossRef] [PubMed]

3. Seifried, H.E.; Anderson, D.E.; Fisher, E.I.; Milner, J.A. A review of the interaction among dietary antioxidants and reactive oxygen species. J. Nutr. Biochem. 2007, 18, 567-579. [CrossRef] [PubMed]

4. Tham, N.T.; Hwang, S.R.; Bang, J.H.; Yi, H.; Park, Y.I.; Kang, S.J.; Kang, H.G.; Kim, Y.S.; Ku, H.O. High-content analysis of in vitro hepatocyte injury induced by various hepatotoxicants. J. Vet. Sci. 2019, 20, 34-42. [CrossRef] [PubMed]

5. Kodavanti, P.R.; Joshi, U.M.; Young, R.A.; Meydrech, E.F.; Mehendale, H.M. Protection of hepatotoxic and lethal effects of $\mathrm{CCl}_{4}$ by partial hepatectomy. Toxicol. Pathol. 1989, 17, 494-505. [CrossRef] [PubMed] 
6. Brattin, W.J.; Glende, E.A., Jr.; Recknagel, R.O. Pathological mechanisms in carbon tetrachloride hepatotoxicity. J. Free Radic. Biol. Med. 1985, 1, 27-38. [CrossRef]

7. Basu, S. Carbon tetrachloride-induced lipid peroxidation: Eicosanoid formation and their regulation by antioxidant nutrients. Toxicology 2003, 189, 113-127. [CrossRef]

8. Chu, S.C.; Hsieh, Y.S.; Lin, J.Y. Inhibitory Effects of Flavonoids on Moloney Murine Leukemia Virus Reverse Transcriptase Activity. J. Nat. Prod. 1992, 55, 179-183. [CrossRef] [PubMed]

9. Kang, J.T.; Kwon, D.K.; Park, S.J.; Kim, S.J.; Moon, J.H.; Koo, O.J.; Jang, G.; Lee, B.C. Quercetin improves the in vitro development of porcine oocytes by decreasing reactive oxygen species levels. J. Vet. Sci. 2013, 14, 15-20. [CrossRef] [PubMed]

10. Kang, C.B.; Kim, C.K.; Song, S.H.; Ha, W.S. Study on mechanism of multistep hepatotumorigenesis in rat: Development of hepatotumorigenesis. J. Vet. Sci. 2001, 41, 583-589.

11. Manna, S.; Bhattacharyya, D.; Mandal, T.K.; Das, S. Repeated dose toxicity of alfa-cypermethrin in rats. J. Vet. Sci. 2004, 5, 241-245. [CrossRef] [PubMed]

12. Tsai, J.C.; Chiu, C.S.; Chen, Y.C.; Lee, M.S.; Hao, X.Y.; Hsieh, M.T.; Kao, C.P.; Peng, W.H. Hepatoprotective effect of Coreopsis tinctoria flowers against carbon tetrachloride-induced liver damage in mice. BMC Complement Altern. Med. 2017, 17, 139. [CrossRef] [PubMed]

13. Misra, H.P.; Fridovich, I. The role of superoxide anion in the autoxidation of epinephrine and a simple assay for superoxide dismutase. J. Chem. Biol. 1972, 247, 3170-3175.

14. Flohe, L.; Gunzler, W.A. Assays of glutathione peroxidase. Methods Enzymol 1984, 105, 114-121. [PubMed]

15. Carlberg, I.; Mannervik, B. Glutathione reductase. Methods Enzymol 1985, 113, 484-490. [PubMed]

16. Kwon, Y.S.; Jang, K.H.; Jang, I.H. The effects of Korean red ginseng (ginseng radix rubra) on liver regeneration after partial hepatectomy in dogs. J. Vet. Sci. 2003, 4, 83-92. [CrossRef] [PubMed]

17. Nielsen, F.; Mikkelsen, B.B.; Nielsen, J.B.; Andersen, H.R.; Grandjean, P. Plasma malondialdehyde as biomarker for oxidative stress: Reference interval and effects of life-style factors. Clin. Chem. 1997, 43, 1209-1214. [PubMed]

18. Reiter, R.J.; Tan, D.X.; Osuna, C.; Gitto, E. Actions of melatonin in the reduction of oxidative stress. A review. J. Biomed. Sci. 2000, 7, 444-458. [CrossRef] [PubMed]

19. Jung, K.; Henke, W. Developmental changes of antioxidant enzymes in kidney and iver from rats. Free Radic. Biol. Med. 1996, 20, 613-617. [CrossRef]

(C) 2019 by the authors. Licensee MDPI, Basel, Switzerland. This article is an open access article distributed under the terms and conditions of the Creative Commons Attribution (CC BY) license (http://creativecommons.org/licenses/by/4.0/). 